\title{
Energy Regulation and the Role of the Market
}

\author{
KEITH F. MILLER
}

This article focuses on the changes and effects of tribunal policies and decisions on industry players since the deregulation of the oil and gas industry. Specifically, it addresses the manner in which the National Energy Board and the Alberla Energy ("NEB") and Utilities Board ("EUB") Uormerly the Energy Resources Conservation Board) have cultivated a forum that fosters free market competition. In particular, the Boards articulate a position of minimal interference in commercial decisions unless public interest or environmental well-being are placed at risk.

Specific examples of applications for the construction of new pipelines and resulting NEB decisions and reasons are further highlighted in this article. In addition, the article looks at similar EUB positions regarding pipeline proliferation projects. Overall, the article juxtaposes the need to facilitate energy customers, distributors and producers in achieving fair market prices with the need for tribunal intervention in balancing such transactions with public interest concerns.
Le présent article porte sur les changements et les effets des politiques et des décisions de justice sur les acteurs de l'industrie depuis la déréglementation de l'industrie du pétrole et du gaz. Il traile plus particulièrement de la fafon dont l'Office national de l'ënergie (ONE) et I'Alberta Energy and Utilities Board (anciennement l'Energy Resources Conservation Board) cultivent un forum propice a la concurrence du marché libre. $\dot{A}$ moins que l'intérêt public ou l'environnement ne soit menacé. les offices optent pour une ingérence minimale dans les décisions commerciales.

Des exemples précis de demande de construction de pipelines et les décisions et motifs de l'ONE sont examinés plus avant. De plus, l'article se penche sur les prises de position de l'EUB envers les projels de prolifération de pipelines. En bref, I'article examine d'une part la nécessité de permeltre aux consommateurs. aux distributeurs et aux producteurs d"ënergie de parvenir à des prix de marché équitables et d'autre part la nécessité que les tribunaux interviennent pour prendre en comple l'intérèt public.

\section{TABLE OF CONTENTS}

I. INTRODUCTION ...................... 420

II. THE EMERGENCE OF MARKET-BASEd REgUlATION ........421

III. THE NEB EXPERIENCE - MARKET-BASED JUSTIFICATION

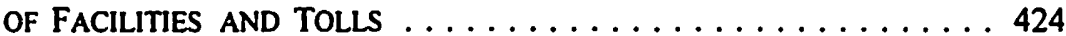
A. CONTRACTUAL JUSTIFICATION
FOR FACILITIES AND TOLLS $\ldots \ldots \ldots \ldots \ldots \ldots \ldots 424$
B. Negotiated SetTlEMentS $\ldots \ldots \ldots \ldots \ldots \ldots \ldots \ldots 430$
C. CONTROL OF LIQUIDS EXTRACTION RIGHTS . . . . . . . . 430
D. OTHER PUBLIC INTEREST MATTERS

Must Be Considered . . . . . . . . . . . . . 4 431

IV. THE EUB EXPERIENCE - NON-INTERFERENCE

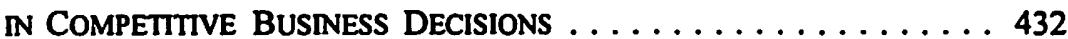

A. Proliferation Policy ................. 432

B. Competitive Pipeline Projects $\ldots \ldots \ldots \ldots \ldots \ldots \ldots 435$

C. DISPOSITION OF LIQUID EXTRACTION RIGHTS . . . . . . . 437

V. Conclusion $\ldots \ldots \ldots \ldots \ldots \ldots \ldots \ldots \ldots \ldots \ldots \ldots \ldots \ldots \ldots$ 


\section{INTRODUCTION}

Deregulation of the Canadian oil and gas industry commenced in 1985 with the execution of the Western Accord of March 28, 1985 on Energy Pricing and Taxation ("Western Accord") and the Agreement on Natural Gas Markets and Prices of October 31, 1985 ("Agreement on Markets and Prices"), both agreements being among the governments of Canada, Alberta, British Columbia and Saskatchewan. The Western Accord stated the objective of the signatory governments as follows:

The Governments of Canada, Alberta, Saskatchewan, and British Columbia are agreed on the need to modify the existing taxation and pricing regime in order to stimulate investment and job creation in the energy sector in Canada and to increase the degree of energy security for all Canadians. The four Governments further agree that these objectives can best be met within a regime of market-sensitive pricing for both oil and gas and within a fiscal regime based on profit-sensitive taxation. To this end, the four Governments agree to replace existing arrangements covering the pricing and fiscal treatment of oil and gas with the provisions set out below. These provisions deal respectively with:

I Deregulation of Crude Oil Prices
II $\quad$ Domestic Natural Gas Pricing
III $\quad$ Fiscal Principles

The intent of the Agreement on Markets and Prices was stated as follows:

In the Western Accord of March 28, 1985 on Energy Pricing and Taxation, the governments of Canada, Alberta, British Columbia and Saskatchewan agreed that a more flexible and market-oriented pricing regime was required for the domestic pricing of natural gas. The present Agreement is intended to create the conditions for such a regime, including an orderly transition which is fair to consumers and producers and which will enhance the possibilities for price and other terms to be freely negotiated between buyers and sellers. This will have favourable effects on investment, employment and trade and will provide energy security for all Canadians. ${ }^{2}$

The Agreement on Markets and Prices set forth principles for the free negotiation of natural gas prices, enhancement of access by Canadian buyers to natural gas supplies and by Canadian producers to natural gas markets, and the fostering of a competitive market for natural gas in Canada consistent with the regulated character of the transmission and distribution sectors of the gas industry.

Many of the market changes which arose as a result of the Western Accord and the Agreement on Markets and Prices occurred in the early years following their execution and now are firmly entrenched in, and facilitate, the market activities of oil and gas industry participants. The evolution of deregulation caused a highly regulated gas market to transform into one which fostered direct sales among willing sellers and buyers, based upon freely negotiated pricing, with transportation being available on an open-access basis. Gone were the days when merchant pipelines, such as TransCanada 
PipeLines Limited ("TCPL"), bought gas directly from producers and sold it to eastern Canadian gas distributors. The twenty-five year surplus test for gas removals from Alberta was relaxed substantially. The National Energy Board's ("NEB") quantitative surplus test was replaced by a procedure which looked to market forces to ensure an adequate supply of gas for Canadians. In more recent years, the principles of market-determined regulation have established the basis for decisions by the NEB to approve pipeline facilities based upon the contractually agreed-to sharing of risks between shippers and pipeline proponents. In addition, freely negotiated agreements on tolls have been recognized by the NEB as a foundation for concluding that tolls are just and reasonable. In Alberta, the Energy Resources Conservation Board ("ERCB"), as succeeded by the Alberta Energy and Utilities Board ("EUB"), has articulated a clear and consistent position that it should not interfere with commercial decisions made in a competitive marketplace, except in the face of significant overriding public interest considerations. Both the NEB and the EUB have recognized that the owners of gas transported by pipelines under their respective jurisdictions are entitled to direct the disposition of liquids entrained in their share of gas in a common gas stream.

This article discusses relevant decisions and policies of the NEB and the EUB which have recognized the importance of market forces in the competitive marketplace. This article also considers the circumstances under which other aspects of the public interest are balanced against market considerations when determining whether an energy project approval should be granted.

\section{The EMERgence of MARKet-Based Regulation}

The principles of the Western Accord and the Agreement on Markets and Prices were referred to by the NEB in its RH-5-85 ("RH-5-85") Reasons for Decision, issued in 1986, respecting the terms and conditions of transportation service offered by TCPL. ${ }^{3}$ In that case, the NEB convened a public hearing in response to paragraph 7 of the Agreement on Markets and Prices under which the NEB was requested to review the appropriateness of duplication of demand charges and the appropriateness of TCPL's then existing policy regarding the availability of T-Service transportation for direct purchase of gas. Prior to the execution of the Agreement on Markets and Prices, the NEB had released its Reasons for Decision in RH-2-85' ("RH-2-85") in which it had previously ruled on these two issues. Therefore, in the $\mathrm{RH}-5-85$ proceeding the NEB decided to review its $\mathrm{RH}-2-85$ decision.

The two issues of concern were as follows. First, duplication of demand charges arose when a customer, who had previously purchased gas through a gas distributor, arranged for direct purchase of its gas requirements. In such cases, the customer paid TCPL's demand toll twice: once to the distributor who was responsible for paying TCPL's demand toll, and again to TCPL for T-Service transportation of the direct 1986).

- NEB, In the Matter of TransCanada PipeLines Limited Application dated 8 February 1985, as revised, for new tolls (effective 1 August 1985) No. RH-2-85 (September 1985). 
purchase gas. The second issue, the availability of T-Service, arose from a provision in TCPL's toll schedule which restricted a customer from obtaining T-Service if the service was used to displace gas supplies previously purchased from TCPL.

With respect to the first issue, the NEB stated that "[d]ouble demand charges frustrate the establishment of a flexible and market-oriented pricing regime for natural gas by imposing a substantial financial penalty on direct purchasers." 5 In order to alleviate that problem, the NEB established a solution known as the operational demand volume which was utilized for the purpose of determining demand tolls. In essence, distributors who purchase gas from TCPL were required to pay the demand charge for only the operating demand volume. The operating demand volume would represent a distributor's contract demand volume less the contract demand volumes which would be displaced by direct sales. As a result, direct purchase customers would be only required to pay demand charges in respect of the direct sales volumes transported by way of TCPL's T-Service.

Concerning the second issue, of availability of T-Service, the NEB stated that it was in the public interest to remove the wording of TCPL's displacement proviso from the T-Service toll schedules. The NEB made this decision "[i]n light of the intent of the Agreement to enable a market-responsive pricing system to operate in Canada...." 6

The objectives of the Agreement on Markets and Prices were again recognized by the NEB in its Reasons for Decision concerning an application by Cyanamid Canada Pipeline Inc. ("Cyanamid"). In that case, Cyanamid proposed to build a short-distance pipeline which would bypass the distribution system of The Consumers' Gas Company Ltd. ("Consumers") for the delivery of gas from the system of TCPL to a fertilizer plant near Welland, Ontario. Although the NEB's conclusion that it had constitutional jurisdiction over the proposed pipeline was successfully appealed, the NEB articulated a clear view concerning the importance of not suppressing market signals with respect to the approval of the Cyanamid pipeline. In determining that the balance of public interest was in favour of approving Cyanamid's pipeline, the NEB stated:

The Board finds that the balance of the public interest lies in [Cyanamid's] favour. The Board comes to this conclusion recognizing that installation of the bypass, should it actually occur, could result in something less than an optimum use of resources. But outweighing this consideration in the Board's view, is the need to allow market signals to flow through to the [Ontario Energy Board] and Consumers'. If the Board were not to approve the bypass, it would be suppressing these market signals. While not making any judgment on what should result from the flow through of such signals, the Board is of the view that the [Cyanamid] bypass is in the public interest in the current circumstances of the move to market sensitive gas pricing.

\section{Supra note 3 at 8.}

Ibid. at 6.

NEB, In the Matter of an Application Under Section 49 and Subsection 59(3) of the National Energy Board Act of Cyanamid Canada Pipeline Inc. No. GH-3-86 (December 1986). 
In further response to the Agreement on Markets and Prices, the NEB commenced a review of its quantitative surplus test which it applied before licensing the export of gas from Canada. The NEB's review ${ }^{9}$ centered upon whether the then existing R/P Ratio Procedure surplus test continued to be appropriate or whether it should be replaced by another procedure. In its GHR-1-87 Reasons for Decision, the NEB stated its view about the relationship of supply and demand of gas in response to marketdetermined pricing:

In the Board's view, market-determined pricing means that natural gas prices should be allowed to vary in response to market forces, and, in turn, natural gas supply and demand should be free to adjust to changes in price. The Board's surplus determination procedures should be consistent with this policy and with the extent to which the policy has been successfully implemented. ${ }^{10}$

Concerning the appropriateness of the R/P Ratio Procedure, the NEB concluded that continuation of the test would be contrary to free market operation. The NEB said:

While the R/P Ratio Procedure has merits, it now appears to the Board that it would be anomalous and contrary to free market operation if the level of supply were to be determined by other than market forces.

For the same reasons, any procedure which would mandate excess productive capacity would not now be appropriate in light of the progress which has been made in implementing the policy of market-determined pricing."

The NEB concluded that "[the] setting aside of any predetermined amount of gas reserves by means of a surplus formula cannot help but interfere with the proper functioning of the market."12 Hence, the NEB implemented the Market-Based Procedure as an alternative to the R/P Ratio Procedure. The new procedure has two basic elements. First, public hearings in respect of which there is a complaints mechanism that affords Canadian gas users the opportunity to object to an export on the basis that they cannot obtain additional gas supplies under contract on terms and conditions (including price) similar to those in the export proposal. The second element of the procedure is ongoing monitoring of the functioning of the marketplace and an analysis of supply, demand and pricing. The NEB continues to regulate the long-term export of gas from Canada utilizing the Market-Based Procedure.

In Alberta, the ERCB also reviewed its quantitative surplus test which was applied before the authorization for removal of gas from the province. ${ }^{13}$ This review was in response to the Agreement on Markets and Prices. Prior to the commencement of the review, Alberta's Minister of Energy wrote to the $\mathrm{ERCB}^{14}$ to state that it was

NEB, In the Matter of Review of Natural Gas Surplus Determination Procedures, No. GHR-1-87 (July 1987).

Ibid. at 6.

Ibid. at 7.

Ibid. at 26.

ERCB, Gas Supply Protection for Alberta, Policies and Procedures Report 87-A (March 1987).

Ibid., A-4 (28 October 1986). 
government policy to provide for the reasonable needs of end users who could not be expected to contract directly for supply needs.

It had been a requirement of the ERCB's surplus test that a twenty-five year supply of gas be maintained for the present and future needs of persons in Alberta. Following its review, the ERCB decided to apply a surplus test which would protect the fifteen year requirement for core markets. Although the ERCB did not eliminate the mandated surplus requirement entirely, it sought to mandate a surplus which would be relatively close to the volume normally contracted by Alberta users, thus lessening the interference of a surplus test with market forces. The ERCB also stated its belief that a restrictive mandated surplus test would not be justified in order to avoid downward pressure on the price of Alberta gas which might occur as a result of deregulation.

\section{THE NEB EXPERIENCE - MARKET-BASED JUSTIFICATION OF FACILITIES AND TOLLS}

\section{A. CONTRACtual Justification for Facilities and TOlls}

When an application is made to the NEB to construct a pipeline, the NEB, prior to granting approval, must be satisfied that the pipeline is and will be required by present and future public convenience and necessity. ${ }^{15}$ Concerning the economic feasibility of a pipeline, the NEB assesses the likelihood that applied-for facilities will be used at a reasonable level over their economic life and the likelihood that costs associated with the pipeline will be recovered. When considering the approval of pipeline tolls, the NEB is required by section 62 of the National Energy Board Act to ensure that all tolls are just and reasonable.

The NEB has established Guidelines ${ }^{16}$ ("Guidelines") which prescribe the information to be filed concerning an application for a gas or oil pipeline certificate pursuant to section 52 of the National Energy Board Act or an order under section 58. Applications for a section 52 certificate must be accompanied by detailed information respecting supply, demand, the purpose, justification and economic evaluation of the facilities, and tolls and financial information. In respect of section 52 certificate applications for gas pipelines, detailed information regarding project-specific gas markets is required by the Guidelines. The information required concerning tolls for section 52 pipelines contemplates a cost-of-service methodology under which rate base, rate of return, rates of depreciation and operating costs are prescribed by the NEB.

Market-based principles have been applied by the NEB in a number of decisions respecting pipeline applications to decide that facilities are needed and that the associated tolls are just and reasonable. Such determinations have been made by the NEB based upon risk-sharing arrangements agreed to between a pipeline company and its shippers. These risk-sharing arrangements arise from agreements under which shippers contract for capacity and agree to pay specified tolls. In all cases considered 
in this section of the article, with one exception, specific tolls for which NEB approval was sought were established by contract and were not subject to cost-of-service methodology.

In January 1995, the NEB released its Reasons for Decision in the GH-4-94 ${ }^{17}$ proceeding concerning the application of Foothills Pipe Lines (Alta.) Ltd. ("Foothills") for approval to construct the proposed Wild Horse Pipeline. That pipeline was intended to connect with the proposed pipeline of Altamont Gas Transmission Company to deliver gas to the western market centre in Wyoming. The tolls for the Wild Horse Pipeline were to be established on a stand-alone basis and thus the cost would not be passed on to shippers on Foothills' prebuild facilities.

The application was not supported by executed firm service agreements; instead, Foothills filed executed precedent agreements which contained several conditions that had to be satisfied before shippers would be required to execute firm service agreements. It was Foothills' position that it would not construct the pipeline without executed fifteen year firm service contracts for full capacity. One of the conditions to be fulfilled required that each shipper inform Foothills that the tolls would be acceptable.

It was Foothills' position that, by advancing its project based upon precedent agreements, it was responding to changes in the marketplace by affording shippers as much time as possible to make their arrangements for gas supply and markets. Since the pipeline would be built only if all conditions of the precedent agreements were satisfied, including supply and market arrangements, one could safely say that the project was market driven. If the market provided the necessary level of support, the pipeline would be constructed. If the market did not support the project, it would not proceed.

In its decision, the NEB took a pragmatic approach to the lack of firm service agreements. This approach was intended to allow the market to operate and determine whether or not the project would proceed:

The Board continues to believe that it should place considerable weight on the existence of binding and unconditional transportation service agreements for 100 per cent of the applied-for capacity as a demonstration of shipper support for new gas pipeline facilities. To date, Foothills has not provided the Board with such agreements.

However, in the case of this application, the Board is prepared to accord Foothills some flexibility by not making the filing of binding service agreements a prerequisite to the granting of an approval. The Board would do so to enable Foothills to advance the project in conjunction with Altamont without prejudicing the target in-service date, while still allowing prospective shippers, competing in an increasingly short-term natural gas market place, time-flexibility in finalizing their transportation agreements. 
The Board believes that, in the particular circumstances of this project, such a position on its part is consistent with allowing market and investment choices by shippers and the project sponsors to be made without undue regulatory interference. At the same time, the Board can be confident that the costs of the facilities will be fully covered for an extended period of time, given Foothills' position that it will not proceed with the project unless it is fully subscribed for a minimum term of 15 years...."

The NEB decided to impose a condition in the certificate for the Wild Horse Pipeline project which required Foothills to file with the NEB, prior to commencement of construction, executed unconditional firm service agreements with a minimum term of fifteen years for full capacity of the pipeline. The NEB had this to say about the requirement for unconditional firm transportation agreements:

The Board wishes to maintain a regulatory climate in which the project sponsors can continue to test the market. If the pipeline becomes fully subscribed for the minimum term of 15 years proposed by Foothills, and if the remaining conditions can also be fulfilled, then the project may proceed in a timely manner to meet the needs of the market place. Otherwise, the pipeline will not be constructed.

In formulating its decision, the Board was influenced by the atypical circumstances of this project and the need for the industry and the regulator to be responsive to the evolving trends of the natural gas market place. ${ }^{19}$

In the GH-1-96 proceeding, the NEB approved an application by Novagas Clearinghouse Pipelines Ltd. ("NCPL") to construct the Pesh Creek Pipeline. ${ }^{20}$ In reaching that decision, the NEB applied market-based principles. The pipeline was supported by firm and interruptible service agreements which specified the tolls to be charged by shippers. The NEB expressed the view that executed agreements for firm and interruptible service demonstrated that the applied-for facilities were required. Concerning tolls, the NEB noted that all shippers had agreed to the charges to be imposed by NCPL and that the transportation fee covered the pipeline's operating costs and contributed to return on capital. The NEB expressly recognized the willingness of NCPL and its shippers to assume all risks related to the project including underutilized capacity:

The Board is also satisfied that the contractual arrangements underpinning the applied-for facilities clearly demonstrate that the parties have found the economics of the Pesh Creek Pipeline Project attractive enough to proceed. Those arrangements similarly demonstrate their willingness to assume all risks, including the risk associated with any undenutilized facilities. In these circumstances, the Board finds the project to be economically feasible."

$18 \quad$ Ibid. at 46.

19 Ibid. at 56.

20 NEB, In the Matter of Novagas Clearinghouse Pipelines Lid. Application dated 12 October 1995, No. GH-1-96 (January 1996). 
In its Reasons for Decision in $\mathrm{OH}-1-95^{22}$ respecting the approval of a pipeline application by Express Pipeline Ltd. ("Express"), the NEB embraced market-based tolling methodology. Express had applied to the NEB for a certificate to construct a crude oil pipeline from Hardisty, Alberta to the international border to connect with the United States segment of the pipeline which would terminate at Casper, Wyoming. Express conducted an open season under which 85 percent of its available capacity was contracted by shippers. The firm service arrangements assured shippers of preferred access to the pipeline. Instead of establishing its tolls using the standard cost-of-service approach, Express offered its shippers three terms of firm service with progressively lower tolls provided for longer-term commitments. As a result of its market-based toll, Express requested relief by the NEB from having to file the detailed cost-of-service information required by the Guidelines. ${ }^{23}$ The NEB granted Express' request.

The NEB's approval of the Express Pipeline project is significant for the following two reasons:

(1) The NEB found that lower tolls, renewal rights and preferred access for shippers who signed contracts were justified because of the financial support provided by such shippers and the sharing of risks with Express. ${ }^{24}$
Although Express proposed to grant preferred access to shippers with contractual commitments, the NEB found that Express had not contravened its common carrier obligations imposed by subsection 71(1) of the National Energy Board Act.

The NEB held that Express' tolls were just and reasonable and noted that the cost-ofservice benchmark was not necessary to make such an evaluation. The NEB relied on the fact that 85 percent of Express' capacity was contracted for by shippers in determining that Express' tolls were market-based and highly competitive in the market. ${ }^{25}$ The NEB also relied on the business judgment of the parties entering into such commitments as a basis for concluding that the tolls were just and reasonable.

Concerning Express' common carrier obligations, the NEB took into consideration the open season conducted by Express and the fact that Express gave all parties an equal opportunity to contract for long-term, secure access on the Express pipeline system. The NEB noted that "[p]otential shippers who chose not to enter into a long-term transportation service agreement did so with the full understanding that they would not receive the same package of services extended to contract shippers." 26 
The Express-type model of market-based tolls was adopted by Federated Pipe Lines (Northern) Ltd. ("Federated Northern") in its application to the NEB ${ }^{27}$ for approval to construct a liquids pipeline from Taylor, British Columbia to Belloy, Alberta. From Belloy, liquids would ultimately be transported to the Fort Saskatchewan area in Alberta. The NEB noted that there were two other proposed pipeline projects competing for liquids supply in the Taylor area for ultimate delivery to the Edmonton and Fort Saskatchewan areas. One of the other projects was a pipeline proposed by NCPL which was the subject of the OH-2-96 ("OH-3-96") proceeding. ${ }^{28}$

Federated Northern offered shippers three service categories, each with a specified toll. The tolls were market-based rather than being derived through a traditional cost-ofservice approach. In its OH-3-96 Reasons for Decision, the NEB stated:

\begin{abstract}
In view of the consultative process that Federated Northem has undertaken with its shippers to develop its proposed tolls, together with the transportation agreements that Federated Northern has been able to sign to date in a highly competitive market, the Board is satisfied that the proposed market-based tolling methodology is appropriate. Concerning Federated Northem's proposal to give shippers who sign transportation agreements lower tolis and preferred access over uncommitted shippers, the Board continues to hold the view that lower tolls, renewal rights and preferred access for contract shippers are justified by the support those shippers provide for the financing of the pipeline and their sharing of the risks associated with the pipeline. 29
\end{abstract}

In both the OH-2-96 and OH-3-96 Reasons for Decision, the NEB found that the existence of signed long-term pipeline transportation agreements presented evidence for the need of the proposed facilities.

In the hearings for each of the NCPL and Federated Northern applications, the issue of liquids extraction rights at Taylor was discussed. The question was raised whether the owner of the existing liquids extraction plant at Taylor, Solex Gas Liquids Ltd. ("Solex"), held the liquids extraction rights for the gas that would be the source of liquids to be transported through the Federated Northern pipeline. In its Reasons for Decision in both hearings, the NEB expressed confidence that "market forces will probably determine how the remaining available supply [of liquids] is committed for transportation from Taylor." ${ }^{30}$ The NEB approved the applied-for facilities of both NCPL and Federated Northern.

In its Reasons for Decision in $\mathrm{OH}-2-97^{31}$ concerning the application of Interprovincial Pipe Line Inc. ("IPL") to reverse its Line 9, the NEB attached great for the Taylor to Belloy Pipeline Project, No. OH-3-96 (April 1997). NEB, In the Matter of Novagas Clearinghouse Lid. Application dated 20 September 1996, as amended, for the Taylor - Boundary Lake Liquids Pipeline, No. OH-2-96 (May 1997). Supra note 27 at 10.

Ibid. at 5; supra note 28 at 5.

NEB, In the Matter of Interprovincial Pipe Line Inc. Application dated I May 1997 for the Line 9 Reversal Project and an application dated 17 July 1997 by United Refining Company for designation of a priority destination on Interprovincial Pipeline, No. OH-2-97 (December 1997). 
weight to two agreements entered into by the refiners ("Refiners") utilize capacity on the reversed Line 9. The first agreement was the CAPP/Refiner Agreement ("CRA"), entered into with the Canadian Association of Petroleum Producers ("CAPP"). The second agreement was the Facilities Support Agreement ("FSA") entered into with IPL. The CRA prescribed certain crude oil pricing events which would trigger the right of the Refiners to request IPL to apply for a reversal of Line 9. Such reversal service was intended to deliver offshore crude oil received in Montreal from the Portland Pipeline to refineries in Ontario. The reversal would reduce the amount of western Canadian crude that could be delivered to the Ontario refineries.

The CRA provides for a sharing of revenue shortfalls and revenue excesses between the Refiners and IPL's older system during the first five years after the commencement of Line 9 reversal service. After the five-year transition period, the Refiners would be at full risk for the payment of tolls to IPL for contracted capacity on Line 9. Such contracted capacity is provided for under the FSA for which the Refiners were granted unapportioned access for the full capacity of the pipeline. The mechanism for revenue shortfall sharing between the Refiners and IPL's older system was opposed by a number of intervenors ${ }^{33}$ on the basis that tolling for a reversed Line 9 should be stand-alone, and that the older system should not cross-subsidize the Refiners' toll payment obligations if throughputs were less than predicted.

In its decision, the NEB referenced its guidelines for negotiated settlements ("Settlement Guidelines"). ${ }^{34}$ The NEB noted that since there had been opposition to the implementation of the CRA and the FSA, the agreements could not be considered negotiated settlements within the meaning of the NEB's Settlement Guidelines. However, the NEB recognized that the tolling methodology applied for by IPL, which arose out of the CRA, was a result of negotiations between CAPP and the Refiners. The NEB stated:

In the RH-2-91 Decision, the Board stated its belief that stand-alone tolls would be the most appropriate methodology for a reversed Line 9. The Board notes that in the current proceeding, no party opposed the principle of stand-alone tolls. It is recognized, however, that the applied-for methodology, which is the result of negotiations between CAPP, the Refiners and Sunoco, is a compromise which would allow for a transition from fully integrated to fully stand-alone tolls. The Board is of the view that it is reasonable, in this case, to have such a transition period in order that participants have adequate time to adjust to changes in oil markets which may result from the reversal. The Board therefore approves the applied-for toll methodology which allows for a transition from a fully integrated to a fully stand-alone toll methodology."3

Ibid. at vi. Imperial Oil, Petro-Canada, Shell Canada Limited and NOVA Chemicals (Canada) Ltd. Alberta Department of Energy, the Small Explorers and Producers Association of Canada, Gulf Canada Resources Limited, Talisman Energy Inc., Renaissance Energy Inc., Alberta Energy Company Lid., Anderson Exploration, Canadian Natural Resources Limited, CANPET Energy Group Inc., Husky Oil Operations Led., Northstar Energy Corporation, Poco Petroleums Ltd., and Rigel Oil \& Gas Led., ibid. at iv and vi. 
The NEB concluded that the existence of the FSA and the obligations undertaken by the Refiners to pay tolls pursuant to that agreement was evidence that a reversed Line 9 would be used and useful over the life of the project. The NEB approved the reversal of Line 9 and IPL's tolling proposal that arose out of the CRA.

\section{B. Negotiated Settlements}

The NEB has encouraged pipeline companies and interested parties to seek resolution of toll and tariff issues through a negotiated settlement process. ${ }^{36}$ The NEB has stated that when a settlement is not opposed by any party, it would normally be able to conclude that the tolls prescribed by the settlement are just and reasonable. This position conforms to the NEB's market-based approach which it has applied when approving facilities and associated tolls based upon risk-sharing among project participants.

The NEB has stated that an acceptable settlement process should satisfy three criteria:

(1) The settlement process should be open and all parties having an interest should have a fair opportunity to participate.

(2) “A negotiated settlement process must not fetter the Board's ability and discretion to take into account any public interest considerations which may extend beyond the immediate concerns of the negotiating parties."

(3) There must be sufficient information available to the NEB to allow it to understand the basis for the agreement and to assess its reasonableness. ${ }^{37}$

\section{Control of Liquids Extraction Rights}

In the MH-2-97 proceeding, ${ }^{38}$ Novagas Canada Ltd. ("NCL") requested that the Board inquire into, among other matters, the right of Westcoast Energy Inc. ("Westcoast") to divert gas transported on its pipeline facilities to the gas liquids stripping plant at Taylor, British Columbia owned by Solex. The final arguments presented in the hearing addressed the authority of Westcoast, under its pipeline Tariff, to divert gas to the Solex Plant. The diversion of gas was pursuant to a Gas Stripping Agreement ("GSA") between Westcoast and Solex which was entered into when Westcoast and Petro-Canada sold the plant to Solex.

The NEB concluded that it was a reasonable interpretation of Westcoast's tariff that Westcoast had the authority to divert the gas stream to Solex in accordance with the

Supra note 34.

Ibid.

NEB, In the Matter of Novagas Canada Ltd., Application dated 12 May 1997 requesting that the Board inquire into the practices of Westcoast Energy Inc. with respect to gas stripping arrangements at Taylor, British Columbia, No. MH-2-97 (October 1997). 
provisions of the GSA. However, with respect to the right of shippers to obtain their natural gas liquids entrained in the Westcoast common stream, the NEB stated:

The role of pipeline companies and the operation of markets have evolved considerably since the implementation of Westcoast's present Tariff provisions. The Board is of the view that, while Westcoast may have been permitted under its present Tariff to divert the gas to the Solex Plant for the stripping of the NGL, it should not be allowed to continue to do so. ${ }^{39}$

The issue of Westcoast's authority to divert gas to the Solex plant arose because NCL had proposed to construct a second liquids stripping plant at Taylor. Therefore, NCL wanted to ensure that Westcoast shippers from whom it would obtain liquids extraction rights could cause Westcoast to deliver gas to the NCL plant. The NEB took the position that it is important for shippers to have the opportunity to choose between Solex and NCL to strip liquids from their gas streams; such choice is an important component of market-based solutions. The NEB stated:

The Board notes that it is the position of Westcoast and Solex that having two straddle plants accessing the gas stream at the McMahon outlet may result in significant extra costs and an unwarranted duplication of facilities. The Board also recognizes, however, that those who ship their gas on [the] Westcoast system through the McMahon plant should be entitled to make business decisions regarding whether Solex or NCL strips the NGL from their gas. It may be that it is ultimately determined that there is a better solution to this issue than having two straddle plants process the residue gas stream at the outlet of the McMahon plant. The Board considers that it is the market which should ultimately determine this matter. However, in order for the best solution to be advanced, the market must be permitted to operate. The Board views competition as the best means of ensuring that any single player or small group of players do not exercise an undue influence on the market. An important element of competition and market-based solutions in the context of this hearing is the extent to which shippers - can exercise the choice to have access to alternative means of getting their products to market. The Board is of the view that the Westcoast shippers ought to have the opportunity to make the choice of whether Solex or NCL will strip the NGL from their gas stream. ${ }^{.0}$

Since the NEB issued this decision, NCL has acquired an interest in the Solex plant which will be expanded to extract incremental liquids volumes.

\section{Other PUblic Interest Matters Must Be Considered}

Obviously, the NEB cannot simply rely on the existence of contracts between a pipeline company and shippers to approve the construction of a new pipeline. The NEB has a public interest mandate which requires it to consider other matters and to balance competing interests. Clearly, an important public interest matter the NEB must take into account is environmental impact. Even if project participants agree to bear the full financial risk of a new pipeline, the NEB must weigh the environmental consequences of such a development against the need to construct such a facility. 
The NEB must also consider matters such as the common carrier obligation imposed upon oil pipelines pursuant to subsection 71(1) of the National Energy Board Act when determining whether contracted capacity arrangements are appropriate. As discussed above, the NEB concluded that the contract capacity arrangements for the Express pipeline project did not contravene Express' common carrier obligations under subsection $71(1) .^{41}$ The NEB reached a similar conclusion with respect to the contract capacity arrangements entered into between Federated Northern and its shippers in the OH-3-96 proceeding. ${ }^{42}$

By contrast, in the Line 9 reversal proceeding, ${ }^{43}$ the NEB directed IPL to keep available for nomination, on a monthly basis, 20 percent of the capacity available on the reversed Line 9.44 The NEB distinguished the open season conducted for the Express pipeline project from the Line 9 reversal open season. The NEB observed that when the Line 9 reversal open season was conducted, "there was considerable uncertainty as to whether the Board would approve the reversal, what the tolls would be, the cost to be underpinned by the FSA, timing of applications to the Board and reversal of the line." ${ }^{15}$ The NEB also took into account the fact that a reversed Line 9 would be the only direct connection to bring offshore crude oil into Ontario and that other parties may wish to ship on Line 9 . In deciding that 20 percent of the capacity should be made available for other shippers, the NEB stated:

The Board recognizes that the Refiners accepted considerable risk in backstopping the Line 9 Reversal Project and that it was reasonable for them to expect priority access as a counterpart to this risk. IPL has clearly indicated it would have not proceeded with this project, without the support by the Refiners, as provided for in the FSA. However, in the Board's view, IPL's unwillingness initially to accept any risk associated with this project, hence requiring 100 percent backstopping by the Refiners, cannot override the rights of others to access the IPL system."

\section{THE EUB EXPERIENCE - \\ NON-INTERFERENCE IN COMPETITIVE BUSINESS DECISIONS}

\section{A. Proliferation Policy}

This section discusses decisions of the EUB (or its predecessor, the ERCB) in which it has articulated the position that it will not intervene in matters that may affect competitive business decisions, provided there are no significant public interest issues at stake. These decisions relate to applications for facilities in respect of which an incumbent facility owner has objected to the construction of new facilities on the basis of unnecessary duplication of facilities. This argument arises out of the EUB's proliferation policy.

$4 \quad$ Supra note 22 at 27.
427 at 14.
$4 \quad$ Supra note 27 note 31.
$4 \quad$ Ibid. at 53.
\&s.
I. $\quad$ lbid.


When an applicant applies for approval to construct facilities such as a pipeline or a gas plant, it is required to satisfy the EUB that there is a need for such facility. As part of that analysis, an applicant is required to consider whether there are alternative facilities available with spare capacity or which may be expanded. In June 1989, Mr. Mink, a board member of the ERCB, presented a speech ${ }^{47}$ which has come to be known as the gas plant proliferation policy. In that speech, Mr. Mink referred to increasing conflicts between development of gas plants and society at large. Mr. Mink emphasized the importance of ensuring "that all the available options to avoid plant proliferation have been seriously investigated and to ensure that the information [provided in an] application is sufficient to convince the Board that the need for a new plant exists."48 In response to the notion that it is preferable for a company to control its own facility rather than utilize the processing facilities of another company, Mr. Mink stated:

This reason is one that the Board has great difficulty with but it is one that is being put forward more and more all the time. The Board does not believe that a company's desire to retain ownership of a processing facility is a reason in itself to approve the application. The notion of each owner processing his own gas on his own leads to more smaller plants which is a root cause of a plant proliferation issue. It also appears to compound industrial impacts on the environments and result in inefficient plant utilization."

In January 1991, the ERCB issued Informational Letter IL $91-1^{\text {s0 }}$ concerning its position on gas plant proliferation. The ERCB expressed its view that operators should continue to explore the use of existing facilities as an alternative to building a new plant. It went on to state that "[it] appreciates that there can be many factors which make a new plant preferable to using an existing one and will not preclude its development if the circumstances warrant a new facility. Each application will continue to be evaluated on its own merits." si

In April of 1996, the EUB issued its Guide $56 .{ }^{52}$ In Guide 56, the EUB expanded the scope of its proliferation policy to include all new oil or gas facilities or pipelines, not just gas plants. The Board restated its view that all existing facilities in the area should be examined to determine whether they represent a viable alternative to the proposed development.

In a number of decisions, ${ }^{53}$ the EUB has taken an extremely consistent approach

F.J. Mink, "The ERCB Position on Gas Plant Proliferation" (Address at InfoTech Gas Plant Optimization Conference, 7 June 1989) [unpublished].

$4 \quad$ Ibid. at 8.

$4 \quad$ lbid. at 9.

so ERCB, Applications for Approval of Gas Processing Schemes - Policy on Plant Proliferation, No. IL $91-1$ (29 January 1991).

lbid. at 1.

Energy Development Application Guide and Schedules, vol. 2 (October 1997) at 3.

ERCB, Westcoast Petroleum Lid. Gas Processing Plant Pipeline Permit 21538, Decision D 85-31, Applications 850337 \& 850580 (24 July 1985) at 3; ERCB, Proceeding resulting from a request by Northwestern Utilities Limited for the Board to Review Decision D 91 -6 pursuant to section 42 
in the face of an objection that applied-for facilities represent an unnecessary duplication of facilities and contravene the proliferation policy. In all cases where the matter has been considered, the EUB has articulated the view that it should not intervene in the competitive business decisions made by energy companies unless it is convinced that such decisions place elements of the public interest at risk. Typically, the EUB has concluded that unless there is a significant environmental impact, some significant adverse effect on public revenues, or an adverse effect on resource conservation or correlative rights, it will not interfere with a company's preference to construct its own facilities. Such facilities have included gas plants and pipelines.

Notwithstanding the EUB's clear direction on the limited circumstances in which it will override the decision of an energy company to construct its own facilities, competing energy companies have utilized the proliferation policy or the duplication of facilities argument as the basis for objecting to applications. The end result of such objections, however, have merely delayed the development of new facilities, not prevented them.

The decision of energy companies to construct their own facilities, rather than using existing facilities, can arise out of the failure of parties to reach agreement on fees or the provision of firm capacity on a timely basis. Furthermore, construction of new facilities may also be integral to a company's long-range plan for the development of its resources within a particular area. Under these circumstances, the EUB has clearly stated that it will not impose commercial relationships upon competing parties unless there are overriding public interest concerns. This approach is certainly consistent with a freely operating marketplace.

of the Energy Resources Conservation Act, Decision D 93-4, Proceeding No. 921563 (29 March 1993) at 2; ERCB, Chancellor Energy Resources Inc. Application to Construct and Operate a Sweet Gas Processing Plant in the Stewart Field, Decision D 93-6, Application No. 921683 (19 May 1993) at 3; EUB, Beau Canada Exploration Lid. Application to Construct and Operate a Natural Gas Pipeline in the Gilby Area, Addendum to Decision D 95-13, Application No. 951747 (8 March 1996) at 5; EUB, Renaissance Energy Lid. Application to Construct and Operate a Sweet Natural Gas Pipeline in the Bittern Lake Area, Addendum to Decision D 96-12, Application No. 1001785 (21 March 1997) at 6; and EUB, Novagas Canada Lid. Application 10 Construct and Operate a Sireet Gas Processing Facility and Associated Pipelines in the Parkland Northeast Area, Decision 97-12 Application No. 1007021 (26 August 1997) at 13. 


\section{B. Competitive Pipeline Projects}

In Decision D 96-13, , $^{\text {4 }}$ the EUB rendered its decision concerning competitive pipelines proposed by Peace Pipeline Ltd. ("Peace"), Federated Pipe Lines Ltd. ("Federated") and NCL. Peace's pipeline was intended to transport crude oil and natural gas liquids, Federated's pipeline was intended to transport crude oil, natural gas liquids and segregated condensate and NCL's pipeline was intended to transport natural gas liquids. The pipelines would deliver the commodities from northwestern Alberta and British Columbia to the Fort Saskatchewan and Edmonton areas.

One of the important issues in the hearing related to the extent of pipeline competition in or near the region then served by existing facilities. Related to that debate was whether more than one pipeline should be approved for construction or whether the EUB should approve only the pipeline it considered to be most in the public interest.

The EUB found that there had been no clear demonstration of need for the capacity of more than one pipeline. The EUB indicated its belief that many potential shippers for the projects were reluctant to commit to any one particular project until it was determined which of the three might be approved. The EUB expressed the following views regarding reliance on market forces:

Given the difficulty of determining the optimal facilities to serve potential shippers, the Board is particularly receptive to the evidence presented concerning the beneficial aspects of competition for the industry, and the view that producers and shippers, who pay for transportation service costs, will determine which facilities should get built. Reliance by the Board on market forces is not unique where there are no significant public-interest issues. Various Board decisions have addressed the matter. For example, note the Board's comment at page 6 of Decision D 88-13, a decision which also involved pipeline applications by three different parties:

"The Board believes it is not appropriate for it to intervene in normal business transactions unless issues are related to matters such as conservation or environmental protection or if it found that facilities would be built despite the lack of need for such facilities."

Similarly, note page 5 of Decision D 95-13, a decision which involved two alternate pipeline proposals:

"In the absence of any public, economic, social, or environmental issues, the Board is not prepared to intervene in normal business decisions made in a competitive marketplace." Operate a High Vapour Pressure/Crude Oil Pipeline and Related Facilities, and an Application to Reverse Flow of High Vapour Pressure Pipelines and Construct Interconnecting High Vapour Pressure Pipelines Between Judy Creek, Swan Hills, Namao and Fort Saskatchewan; Novagas Clearinghouse Lid. Application to Construct and Operate a High Vapour Pressure Pipeline and Related Facilities, Decision D 96-13, Applications No. 960198, 960621, 960627 \& 960622 (24 January 1997). 
The Board believes that the applications before it should be considered in light of these comments. With respect to all [three] applications, the Board does not consider that there are any compelling social, economic, environmental, or technical reasons for rejection. Accordingly, in the circumstances of this case, the Board embraces the concluding comments of Decision D 88-13:

"The Board realizes that the construction of any of the applied-for pipelines is dependent upon their commercial viability which hinges in turn on the contractual arrangements in place. The Board realizes it is these arrangements that will partially dictate which pipelines are built."

The Board is prepared to approve all [three] applications before it and to rely upon business decisions made in the competitive marketplace to ensure economic, orderly, and efficient development of the pipeline facilities.

The Board notes NCL's request that its application be approved exclusively so as to give NCL at least a 15 to 18-month competitive advantage to establish its project. However, the Board considers that this would be an unwarranted intervention in the marketplace. Furthermore, the Board believes it would be inequitable to deny the competing applications which also satisfy all regulatory requirements."

This decision reemphasizes the EUB's reluctance to intervene in commercial decisions made under competitive circumstances, a position which is consistent with that expressed in the proliferation policy decisions. This decision also endorses a "letthe-market-decide" approach to determining which one of several competing proposals would be built.

Concerning the possibility of pipeline proliferation arising from the approval of the three pipeline projects, the EUB had the following to say:

. The Board notes that there is considerable evidence indicating the likelihood that not all three projects will proceed at the same time, and that some additional capacity in an area of increasing production will encourage further resource development. The Board believes that, upon issuance of this decision, the applicants will re-evaluate their proposals and proceed prudently with their business plans to ensure economic, orderly, and efficient development. Therefore, the Board is not concemed that approving all three proposals will result in pipeline proliferation.6

This statement recognizes that a company is not likely to construct a pipeline without sufficient market support to justify the associated financial risk. 


\section{Disposition of LIQuids Extraction Rights}

In Decision D 96-7,, 57 concerning the application of Gulf Canada Resources Limited ("Gulf") to extract liquids from gas sidestreamed from the system of NOVA Gas Transmission Ltd. ("NGTL"), the EUB articulated a very strong and clear position concerning the right of owners to control the disposition of their resources. Gulf proposed to receive gas at its Strachan gas plant from NGTL by way of a short-distance tie-in. Gulf proposed to extract liquids from the volume of gas Gulf injects into the NGTL system upstream of Strachan. Gulf's application was opposed by a number of parties including the owners of liquid extraction straddle plants in Alberta.

One of the key issues raised by opposing intervenors was a challenge to the legal right of Gulf to extract liquids from gas transported on the NGTL system, prior to delivery at a designated delivery point. The EUB concluded that Gulf was legally entitled to sidestream its share of the common stream in NGTL. While expressing its views on this issue, the EUB offered the following comment related to market forces and the disposition of resources:

The Board has maintained that, subject only to public interest issues, the discretion to use and direct the disposition of resources should be left to market forces or as per conditions agreed to by contract." $"$ s8

The straddle plant owners advanced various arguments as to why approval of Gulf's application would be contrary to the public interest. Included as part of the evidence of the owners was a social cost-benefit report which indicated that there would be a net cost to Alberta as a result of approval of Gulf's application. The plant owners expressed concern that their per unit operating costs would increase as a result of the reduction of liquids content in the NGTL common stream. In response to the social cost-benefit analysis, the EUB concluded that the absence of a net social benefit would not be an important reason for denying Gulf's application. The EUB held that adopting such an approach would require it to intervene in many industry decisions which it believed to be better left in the commercial arena. The EUB concluded that straddle plant owners should protect their commercial interests through contracts with producers. It had been argued before the EUB that if straddle plants offered competitively attractive terms for extraction rights, the incentive to undertake a sidestream project would be diminished or eliminated.

The EUB recognized that the approval of Gulf's application could lead to further sidestreaming projects which, in the EUB's view, would become a significant concern if they were to threaten the long-term viability of the straddle plant systems in Alberta. On the basis of restrictions which would limit sidestreaming to existing facilities and to the proprietary gas of the gas plant owner, the EUB expressed its belief that the number of future sidestream applications would be limited. 


\section{v. Conclusion}

Both the NEB and the EUB have clearly expressed a desire to have energy projects proceed in response to market signals. The need for new facilities can be demonstrated by the willingness of market participants to bear the associated financial risks. Both boards have recognized the right of resource owners to control the disposition of their resources. Such control involves the opportunity to chose between market options. Interference by either board in the business decisions of market participants can be expected only when there is an overriding public interest reason. Otherwise, the oil and gas marketplace can be expected to operate with minimal regulatory interference. 